\title{
A SIMPLE METHOD OF CALCULATING VENTILATORY REQUIREMENTS IN CHILDREN
}

\author{
RaYNald Déry, M.D., F.R.C.P.(c)"
}

Clinical Monitoring of ventilation with ventilometers is currently widely in use in anaesthesia, and there is no doubt that this has resulted in considerable improvement in the care of anaesthetized patients. In many hands, however, this practice seems to be restricted to adult patients because the anaesthesiologist is unaware of the exact norms of ventilation for children. One can easily remember that a man of normal build requires 500 c.c. of tidal air 12-16 times a minute, and assuming that every adult is ventilated according to these parameters leads to no gross sin. But the matter is quite different when we face children with their varying sizes and ages; nevertheless, removing $\mathrm{CO}_{2}$ from a child and oxygenating him adequately is still as vitally important as it is in an adult. Unsuspected hypoventilation may cause catastrophic results in children and gross hyperventilation may damage their fragile lungs.

The trouble with the estimation of ventilation requirements in children originates from their ever changing weight, length, and metabolic needs. A scientific approach to this problem has been contributed by Radford's nomogram. ${ }^{1}$ But this nomogram is not always at hand and, even if it is, the use of the nomogram looks cumbersome to many.

We have found that, by using a simple equation, we can approximately duplicate the adequacy (and limitations) of this nomogram. All we need is a pen, a sheet of paper, and a notion of the child's weight. The calculation is based on the value of the anatomic dead space, which is constant at 1 c.c. per pound of body weight for children and adults.

Let us take as an example a child of 30 pounds. His calculated dead space will be 30 c.c. On the other hand, let us take as a reference an adult with a dead space of 150 c.c. and a tidal volume of 500 c.c. We can build with these three numbers the equation that will answer our problems:

$$
\begin{aligned}
150 \text { c.c. } \rightarrow 500 \text { c.c. } \\
30 \text { c.c. } \rightarrow x=100 \text { c.c. }
\end{aligned}
$$

This is the tidal air which, when multiplied by the spontaneous breathing frequency of that particular child, will indicate the required pulmonary ventilation. From the interrelation between the two constants ( 150 and 500 c.c.) in the equation, we obtain this simple formula:

$$
\text { tidal volume }=\text { weight in pounds } \times 3 \frac{13}{3}
$$

The logic of this equation is not entirely sound: a child is not a diminutive adult. However, we have found, after multiple comparisons with Radford's

*From the Department of Anaesthesia, Hôtel-Dieu Hospital, Québec, P.Q. 
nomogram, that this calculation is valuable in children of all ages and weights, from the newborn to the adolescent. We hope that it will be useful to other anaesthesiologists who, with their clinical judgment alone, have to keep within physiological limitations the norms of ventilation.

\section{REFERENCES}

1. Radford, E. P. JR. Ventilation Standards for Use in Artificial Respiration. J. Appl. Physiol. 7: 451 ( 1955 ).

2. Adprant, J. Appraisal of Current Concept in Anesthesiology, p. 77. The C. V. Mosby Company, St. Louis (1961).

3. Conroe, J. H., Jr.; Foster, R. E.; DuBois, A. B.; Briscoe, W. A.; and Carlsen, E. The Lung, 2nd ed., p. 328. Year Book Medical Publishers, Chicago (1962). 